\title{
MANEJO ECOFISIOLÓGICO DAS GRAMÍNEAS Megathyrsus maximus (Panicum maximum) cv. TANZÂNIA, MOMBAÇA E MASSAI
}

\author{
Rafael Kill-Silveira ${ }^{1}$
}

\begin{abstract}
RESUMO
Objetivou-se com esta revisão apresentar informações práticas referentes ao manejo de algumas subespécies de gramíneas tropicais da espécie Megathyrsus maximus e sua relação com a composição bromatológica e resposta de crescimento a adubação e ao processo de colheita pelos animais, bem como o efeito deste sobre a estrutura do pasto. Devido a sazonalidade da intensidade luminosa e principalmente do regime de chuvas é importante esclarecer que para os sistemas de produção a pasto (sistema de lotação contínua ou intermitente) devem ser executadas estratégias para o período de entressafra (secas), estas estratégias podem ser de suplementação (com concentrado e/ou volumoso), variação da taxa de lotação, ou ambas. Independentemente de outras variáveis para o capim-Massai e para as outras cultivares estudadas o período de colheita ideal se dá em plantas com 3,5 $\pm 0,5$ folhas expandidas. De maneira geral para Megathyrsus maximus cv Tanzânia sob regime de lotação contínua e carga animal variável, recomenda-se a altura de pastejo entre 40 e $60 \mathrm{~cm}$, e para lotação intermitente (pastejo rotacionado) o ideal é a entrada com $\pm 65 \mathrm{~cm}$ de dossel (parte aérea) e 25 a $30 \mathrm{~cm}$ para o resíduo pós pastejo. Ao ser utilizado como silagem este mesmo cultivar deve ser cortado entre 42 e 63 dias após o plantio. Para o capim-Mombaça em regime de lotação intermitente a entrada dos animais deve ocorrer com altura aproximada de $80 \mathrm{~cm}$ e saída de $40 \mathrm{~cm}$, e para lotação contínua a altura ideal é de 50 a $75 \mathrm{~cm}$. O manejo correto das pastagens é um processo complexo devido às variações das condições climáticas ao longo do ano, diferentes tipos de solo (com características físicas e químicas diferentes), categorias e hábitos de pastejo das diferentes espécies animais, e ainda à grande diversidade de cultivares de capim que são lançados sem estudos necessários para o conhecimento do comportamento destas espécies e as aplicações práticas para a perfeita compreensão dos manejadores. Adicionalmente podemos destacar ainda a falta de assessoria técnica para o aumento da eficiência produtiva essencial para que os produtores saiam da condição de apenas exploradores dos recursos disponíveis necessários para a produção animal.
\end{abstract}

Palavras chave: Forragem, pastejo, pasto, silagem.

\section{ECOPHYSIOLOGICAL MANAGEMENT OF GRASSES Megathyrsus maximus (Panicum maximum) cv. TANZÂNIA, MOMBAÇA AND MASSAI}

\begin{abstract}
The aim with this review was to present practical information regarding the management of some tropical grasses species of the Megathyrsus maximus species and its relationship with bromatological composition and growth response to fertilization and the harvesting process by animals, as well as the effect of this on the pasture structure. Due to the seasonality of the light intensity and mainly the rainfall regime it is important to clarify that for pasture production systems (continuous or intermittent stocking system) strategies should be implemented for the off-season forage production (dry), it they may be supplementation (with concentrate and/or voluminous food), stocking rate variation, or both. Regardless of other variables for Massai grass and for the other cultivars studied, the ideal harvest period occurs in plants with $3.5 \pm 0.5$
\end{abstract}

\footnotetext{
${ }^{1}$ Universidade do Estado de Mato Grosso. killsilveira.r@gmail.com
} 
leaves expanded. In general for Megathyrsus maximus cv Tanzania under continuous stocking (continuous grazing) and variable number of animals, grazing height between 40 and $60 \mathrm{~cm}$ is recommended, and for intermittent stocking (rotated grazing) the entry with $\pm 65 \mathrm{~cm}$ canopy (aerial part) is ideal and 25 to $30 \mathrm{~cm}$ for the residue after grazing. When used with silage this same cultivar should be cut between 42 and 63 days after planting. For Mombasa grass under intermittent stocking, the animals should enter at a height of approximately $80 \mathrm{~cm}$ and exit at $40 \mathrm{~cm}$, and for continuous stocking the ideal height is 50 to $75 \mathrm{~cm}$. Correct pasture management is a complex process due to varying climatic conditions throughout the year, different soil types (with different physical and chemical characteristics), categories and grazing habits of different animal species, and the diversity of cultivars of grass that are released without studies necessary for the knowledge of the behavior of these species and the practical applications for the perfect understanding of the managers. In addition we can also highlight the lack of technical advice to increase the productive efficiency essential for producers to leave the condition of only exploiters of available resources needed for animal production.

Key words: Forage, grazing, pasture, silage.

\section{MANEJO ECOFISIOLÓGICO DE LAS GRAMÍNEAS Megathyrsus maximus (Panicum maximum) cv. TANZÂNIA, MOMBAÇA E MASSAI}

\section{RESUMEN}

El objetivo con esta revisión fue presentar información práctica sobre el manejo de algunas subespecies de especies de gramíneas tropicales de Megathyrsus maximus y su relación con la composición bromatológica y la respuesta de crecimiento a la fertilización y el proceso de recolección por parte de los animales, así como el efecto de esto en el estructura del pasto. Debido a la estacionalidad de la intensidad de la luz y principalmente al régimen de lluvias, es importante aclarar que para los sistemas de producción de pasturas (sistema de pastoreo continuo o intermitente) se deben implementar estrategias fuera de temporada (seco), pueden ser suplementos (con concentrado y/o forraje), variación de la tasa de almacenamiento de los animales, o ambos. Independientemente de otras variables para el pasto Massai y para los otros cultivares estudiados, el período ideal de cosecha ocurre en plantas con $3.5 \pm 0.5$ hojas expandidas. En términos generales, para Megathyrsus maximus cv Tanzania, con almacenamiento continuo ( pastoreo continuo) y número de animales variable, se recomienda una altura de pastoreo entre 40 y $60 \mathrm{~cm}$, y para el almacenamiento intermitente (pastoreo rotativo), la entrada con dosel (parte aérea) de $\pm 65 \mathrm{~cm}$ es ideal, y de $25 \mathrm{a} 30 \mathrm{~cm}$ para el residuo después del pastoreo. Cuando se usa con ensilaje, este mismo cultivar debe cortarse entre 42 y 63 días después de la siembra. Para los pastos de Mombasa con almacenamiento intermitente los animales deben ingresar a una altura de aproximadamente $80 \mathrm{~cm}$ y salir a $40 \mathrm{~cm}$, y para el almacenamiento continuo la altura ideal es de 50 a $75 \mathrm{~cm}$. El manejo correcto de los pastos es un proceso complejo debido a las condiciones climáticas variables durante todo el año, los diferentes tipos de suelo (con diferentes características físicas y químicas), las categorías y los hábitos de pastoreo de diferentes especies animales, y la gran diversidad de cultivares de pasto que se libera sin los estudios necesarios para conocer el comportamiento de estas especies y las aplicaciones prácticas para la perfecta comprensión de los administradores. Además, también podemos destacar la falta de asesoramiento técnico para aumentar la eficiencia productiva esencial para que los productores dejen la condición de solo explotadores de los recursos disponibles necesarios para la producción animal.

Palavras claves: Ensilaje, forraje, pastoreo, pasto. 


\section{INTRODUÇÃO}

No Brasil uma das principais causas da baixa rentabilidade do sistema de produção pecuário é a baixa produtividade das áreas de pastagens, com a característica de falta de conhecimento do manejo do pasto aplicado às diferentes espécies e/ou cultivares utilizados nos diferentes ambientes (1). A maioria dos sistemas de produção pecuária é baseada em pastagens, sendo de fundamental importância que seu uso esteja associado a práticas de manejo sustentáveis, para que ocorra a manutenção da produtividade ao longo dos anos sem o comprometimento da normalidade do ecossistema (2). Principalmente em uma situação em que já utilizamos mais da metade das reservas naturais, inclusive os fertilizantes (3).

Dentre os principais fatores que influenciam a perenidade e a produtividade das gramíneas forrageiras encontram-se o manejo adotado, e os componentes estruturais, tais como a densidade populacional de perfilhos e o número de folhas vivas por perfilhos, a relação folha/colmo, o tamanho da folha, aliados às características morfogênicas (alongamento de folhas e colmos, período de vida e aparecimento das folhas), as variáveis ambientais (luz, temperatura, água e nutrientes) (4).

As principais causas da degradação das pastagens é a escolha da forrageira inadequada de acordo com as características edafoclimáticas do local a ser implantada, a utilização incorreta das práticas de conservação de solos, a ausência de manutenção da fertilidade do solo e a alta taxa de lotação animal (5). A produção das gramíneas tropicais principalmente as do gênero Megathyrsus é maior no período das águas, quando há grande quantidade e alta qualidade nutricional, e menor no período da seca, devido a diminuição da precipitação e da incidência solar, ocorrendo queda da quantidade e na qualidade forrageira (6). Na região do Cerrado as gramíneas mais utilizadas na formação das pastagens se encontram as dos gêneros Panicum e Brachiaria (7).

O principal elemento que determina a capacidade de suporte de uma pastagem é a produção de biomassa, por isso se destaca a grande importância de se conhecer estes elementos para que se compreenda como as estratégias de manejo (ajustes da taxa de lotação, adubação, irrigação, e outros) os influenciam (8). Há fatores intrínsecos (eficiência de captação e utilização dos recursos disponíveis) e extrínsecos (radiação, temperatura, umidade e fertilidade do solo e outros) que afetam a produção de biomassa, e esta deve ser acompanhada da utilização pelos animais no momento correto para que a forragem esteja com melhor valor nutricional (9).

Diante do exposto objetivou-se com esta revisão apresentar informações práticas referentes ao manejo de algumas subespécies de gramíneas tropicais da espécie Megathyrsus maximus e sua relação com a composição bromatológica e resposta de crescimento a adubação e ao processo de colheita pelos animais, e o efeito deste sobre a estrutura do pasto.

\section{Composição bromatológica e resposta a adubação}

Devido à sazonalidade pluviométrica e de incidência solar encontrada em todo o Brasil, logicamente que em algumas regiões há uma maior severidade e intensidade na duração, e podemos encontrar a mesma espécie de gramínea com diferente composição bromatológica nas diferentes estações e regiões e em diferentes níveis de adubação e composição do solo. Os teores de macrominerais encontrados na parte aérea de Megathyrsus maximus cvs. Massai e Mombaça em seis idades de crescimento $(35,55,75,95,115$, e 135 dias após a semeadura), cultivados em casa de vegetação, revelou que com o avanço da idade das forrageiras houve uma redução nos teores de macrominerais em ambas as variedades (10).

De acordo com Freitas et al. (11), ao avaliarem a composição químico-bromatológica do capim Mombaça, utilizando quatro doses de N (70, 140, 210 e $280 \mathrm{~kg}$ de N ha- ${ }^{1}$ ano-$\left.^{-1}\right)$, na forma de uréia para o teor de PB houve acréscimo linear com o aumento das doses de N (Figura 1). 
Em relação aos percentuais de FDN, FDA e HEM (Tabela 1), não se observou diferenças significativas para nenhuma das doses testadas, já para os teores foliares de N, K, S, Mn e Zn, aumentaram de acordo com o aumento da dose de nitrogênio, porém não influenciou os teores de $\mathrm{P}, \mathrm{Cu}, \mathrm{Fe}, \mathrm{Ca}$ e $\mathrm{Mg}$ (Tabelas 2 e 3).

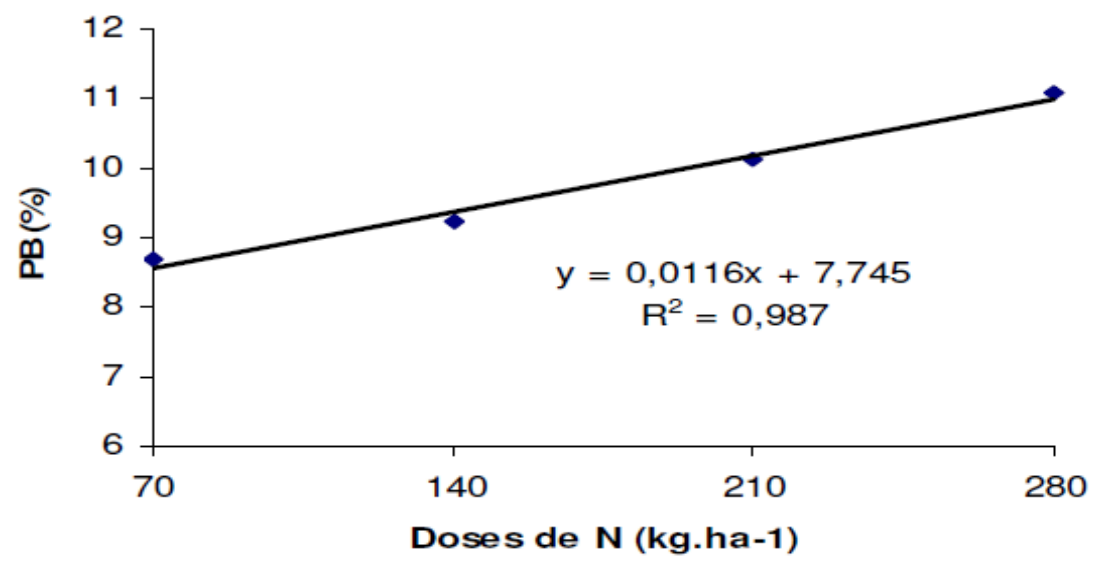

Figura 1. Teores médios de proteína bruta dos cortes realizados no capim Mombaça em função das diferentes doses de $\mathrm{N}$.

Em relação ao teor de proteína o mesmo comportamento foi descrito por Silva et al. (12), pois quando avaliaram quatro doses de nitrogênio usando como fonte o sulfato de amônio, no período seco e chuvoso e em duas alturas residuais, onde observaram que os valores de proteína bruta nas doses aplicadas de: $0,100,300$ e $500 \mathrm{~kg} \mathrm{ha}^{-1}$ de $\mathrm{N}$ foram: 8,7; 8,8; 9,4 e 10,6\% na altura residual de $0,20 \mathrm{~m}$; e 7,5;8,4; 9,1 e $10,2 \%$ na altura residual de $0,40 \mathrm{~m}$, no período chuvoso. No período seco, os teores foram: 6,$47 ; 6,77 ; 8,22 ; 8,23 \%$ e de 7,$50 ; 7,43 ; 8,14$ e $8,34 \%$ para as duas alturas residuais, respectivamente. Houve também efeito sobre a interação entre doses versus alturas, nas doses de 100 e $300 \mathrm{~kg} \mathrm{ha}^{-1}$ de $\mathrm{N}$, com valores médios no período chuvoso de $20,5 \%(0,20 \mathrm{~m}) ; 24,7 \%(0,40 \mathrm{~m})$ e $17,5 \%(0,20 \mathrm{~m}) ; 14,1 \%(0,40 \mathrm{~m})$, respectivamente.

Tabela 1. Teores médios de fibra em detergente neutro (FDN) (\%), de fibra em detergente ácido (FDA) (\%) e de hemicelulose (HEM) (\%) do capim Mombaça em função das doses de $\mathrm{N}$.

\begin{tabular}{cccc}
\hline \hline Doses de N $\left(\right.$ kg ha. $\left.^{-1}\right)$ & FDN (\%) & FDA (\%) & HEM (\%) \\
\hline \hline 70 & $73,58 \mathrm{a}$ & $43,91 \mathrm{a}$ & $29,67 \mathrm{a}$ \\
140 & $73,57 \mathrm{a}$ & $39,39 \mathrm{a}$ & $34,28 \mathrm{a}$ \\
210 & $73,09 \mathrm{a}$ & $40,19 \mathrm{a}$ & $33,90 \mathrm{a}$ \\
280 & $73,76 \mathrm{a}$ & $40,78 \mathrm{a}$ & $32,97 \mathrm{a}$ \\
\hline \hline CV\% & 1,01 & 12,89 & 16,44 \\
\hline \hline
\end{tabular}

Médias seguidas de letras iguais indicam que as mesmas não diferem entre si pelo Teste de Scott-Knott $(P>0,05)$.

Os teores de FDN dentro deste intervalo foram encontrados por Ribeiro et al. (13), com valores médios de 70,5 $\pm 0,40$ para o período da seca, e valores médios de $76,4 \pm 0,70$ para o período das chuvas para lâmina foliar em pastagens irrigadas. Resultados similares foram encontrados por Janusckiewicz et al. (14), pois ao avaliarem dois períodos de descanso(d) (25 e 35 dias) e duas alturas de resíduo (r) pós-pastejo $(30$ e $50 \mathrm{~cm})$, com arranjo fatorial 2x2, observaram valores de FDN 73,42, 72,94, 71,85 e 73,62\%, para 25d30r, 25d50r, 35d30r e 35d50r, respectivamente, e encontraram valores de FDA de 44,13, 45,06, 45,90 e 44,26 para 
25d30r, 25d50r, 35d30r e 35d50r, respectivamente, ambos com base no percentual da MS das folhas. Ao avaliarem a matéria mineral (\% da MS), observaram valores de 10,23, 10,44, 10,29 e $11,07 \%$ para $25 \mathrm{~d} 30 \mathrm{r}, 25 \mathrm{~d} 50 \mathrm{r}, 35 \mathrm{~d} 30 \mathrm{r}$ e $35 \mathrm{~d} 50 \mathrm{r}$, respectivamente.

Tabela 2. Teores médios de nitrogênio $(\mathrm{N})$, de fósforo $(\mathrm{P})$, de potássio $(\mathrm{K})$, de cálcio $(\mathrm{Ca})$, de magnésio $(\mathrm{Mg})$ e de enxofre $(\mathrm{S})$ do capim Mombaça em função das doses de $\mathrm{N}$.

\begin{tabular}{ccccccc}
\hline & $\mathrm{N}$ & $\mathrm{P}$ & $\mathrm{K}$ & $\mathrm{Ca}$ & $\mathrm{Mg}$ & $\mathrm{S}$ \\
\cline { 2 - 7 } Tratamentos & dag kg-1* & & & & & \\
\hline \hline $70 \mathrm{~kg} \mathrm{~N} \mathrm{ha.-}{ }^{1}$ & $1,38 \mathrm{c}$ & $0,30 \mathrm{a}$ & $2,46 \mathrm{~b}$ & $0,50 \mathrm{a}$ & $0,22 \mathrm{a}$ & $0,13 \mathrm{c}$ \\
$140 \mathrm{~kg} \mathrm{~N} \mathrm{ha.}^{-1}$ & $1,50 \mathrm{~b}$ & $0,28 \mathrm{a}$ & $2,71 \mathrm{a}$ & $0,50 \mathrm{a}$ & $0,25 \mathrm{a}$ & $0,16 \mathrm{~b}$ \\
$210 \mathrm{~kg} \mathrm{~N} \mathrm{ha.}^{-1}$ & $1,65 \mathrm{a}$ & $0,29 \mathrm{a}$ & $2,88 \mathrm{a}$ & $0,49 \mathrm{a}$ & $0,24 \mathrm{a}$ & $0,18 \mathrm{a}$ \\
$280 \mathrm{Kg} \mathrm{N}{ }^{1}{ }^{1}$ & $1,68 \mathrm{a}$ & $0,30 \mathrm{a}$ & $3,04 \mathrm{a}$ & $0,48 \mathrm{a}$ & $0,25 \mathrm{a}$ & $0,19 \mathrm{a}$ \\
\hline \hline CV\% & 4,97 & 10,91 & 10,84 & 7,80 & 14,48 & 10,99 \\
\hline \hline
\end{tabular}

Médias seguidas de letras iguais (na vertical) indicam que as mesmas não diferem entre si pelo Teste de ScottKnott $(\mathrm{P}>0,05) . * \mathrm{dag} / \mathrm{kg}=\%$

Resultado semelhantes para os teores de $\mathrm{N}$ foram encontrados com a forrageira Massai, pois a calagem e adubação com $\mathrm{P}$ e $\mathrm{N}$ aumentaram significativamente as concentrações de $\mathrm{N}$, $\mathrm{P}, \mathrm{Ca}$ e $\mathrm{Mg}$ nas folhas diagnósticas, os efeitos mais importantes são os aumentos na concentração do $\mathrm{P}$ foliar. A diferença encontrada para os teores de $\mathrm{P}, \mathrm{Ca}$ e $\mathrm{Mg}$ pode ser devida a calagem e a adubação com $P$ (15).

Comportamento similar foi encontrado somente para $\mathrm{K}$ e $\mathrm{Ca}$, pois avaliando-se a relação entre minerais e matéria seca de amostras da parte aérea e raiz de capim-tanzânia adubadas com níveis crescentes de nitrogênio $(0,60,120,180 \mathrm{~kg} / \mathrm{ha})$ na forma de chorume bovino, analisados por meio dos procedimentos multivariados: análise de função discriminante e análise de componentes principais, observou-se que as variáveis mais importantes em termos de variação foram $\mathrm{Ca}$ na raiz, $\mathrm{K}$ na folha, $\mathrm{K}$ na planta, $\mathrm{Mg}$ na folha, $\mathrm{P}$ na folha e $\mathrm{P}$ na raiz (16).

Tabela 3. Teores médios de cobre $(\mathrm{Cu})$, de ferro $(\mathrm{Fe})$, de manganês $(\mathrm{Mn})$ e de Zinco $(\mathrm{Zn})$ do capim Mombaça em função das doses de N.

\begin{tabular}{|c|c|c|c|c|}
\hline & $\mathrm{Cu}$ & $\mathrm{Fe}$ & $\mathrm{Mn}$ & $\mathrm{Zn}$ \\
\hline Tratamentos & mg kg_1* & & & \\
\hline 70 kg N ha-1 & $8,55 \mathrm{a}$ & $22,56 \mathrm{a}$ & $6,88 \mathrm{~b}$ & $18,27 \mathrm{~b}$ \\
\hline $140 \mathrm{~kg} \mathrm{~N} \mathrm{ha-} 1$ & $9,03 \mathrm{a}$ & $23,76 \mathrm{a}$ & $7,14 \mathrm{~b}$ & $18,40 \mathrm{~b}$ \\
\hline 210 kg N ha- ${ }^{1}$ & 9,09 a & $25,11 \mathrm{a}$ & $8,35 \mathrm{a}$ & $19,83 \mathrm{a}$ \\
\hline $280 \mathrm{~kg} \mathrm{~N} \mathrm{ha-}{ }^{1}$ & $9,88 \mathrm{a}$ & $28,84 \mathrm{a}$ & $9,57 \mathrm{a}$ & $20,86 \mathrm{a}$ \\
\hline $\mathrm{CV} \%$ & 19,61 & 19,92 & 11,75 & 19,37 \\
\hline
\end{tabular}

Médias seguidas de letras iguais (na vertical) indicam que as mesmas não diferem entre si, pelo Teste de ScottKnott $(\mathrm{P}>0,05)$. *mg/kg = PPM.

Ao avaliar a influência de quatro intervalos de corte (4, 6, 8 e 10 semanas) e três doses de $\mathrm{K}_{2} \mathrm{O}(0,100$ e $200 \mathrm{~kg} / \mathrm{ha})$ na produção de forragem de Megathyrsus maximus cv. Tanzânia, Sousa et al. (17), verificaram que houve aumento linear na altura dos perfilhos na produção de MS tanto com os maiores intervalos de corte bem como para o aumento nas doses de potássio, no entanto os tratamentos não influenciaram na densidade de perfilhos e na relação folha/colmo.

Com o intuito de se melhorar as condições que propiciem a implantação e o desenvolvimento das plantas forrageiras vêm sendo utilizadas a intensificação da mecanização. No entanto essa prática pode causar danos às propriedades físicas do solo, tanto quanto pelo 
excesso ou pela inadequação de práticas às quais o solo é submetido, desde o seu manejo até a colheita da cultura que nele se estabeleceu (18).

Os atributos físicos do solo referem-se a densidade e consequentemente a porosidade, e esses atributos influenciam de maneira significativa a produtividade, pois ao avaliarem a compactação do solo em casa de vegetação com quatro níveis de compactação, 1,0; 1,2; 1,4 e $1,6 \mathrm{Mg} \mathrm{m}^{-3}$, verificaram que houve redução linear nos valores de massa seca da folha (MSF) e na massa seca da parte aérea (MSPA) com aumento da compactação do solo (Figura 2) (19).
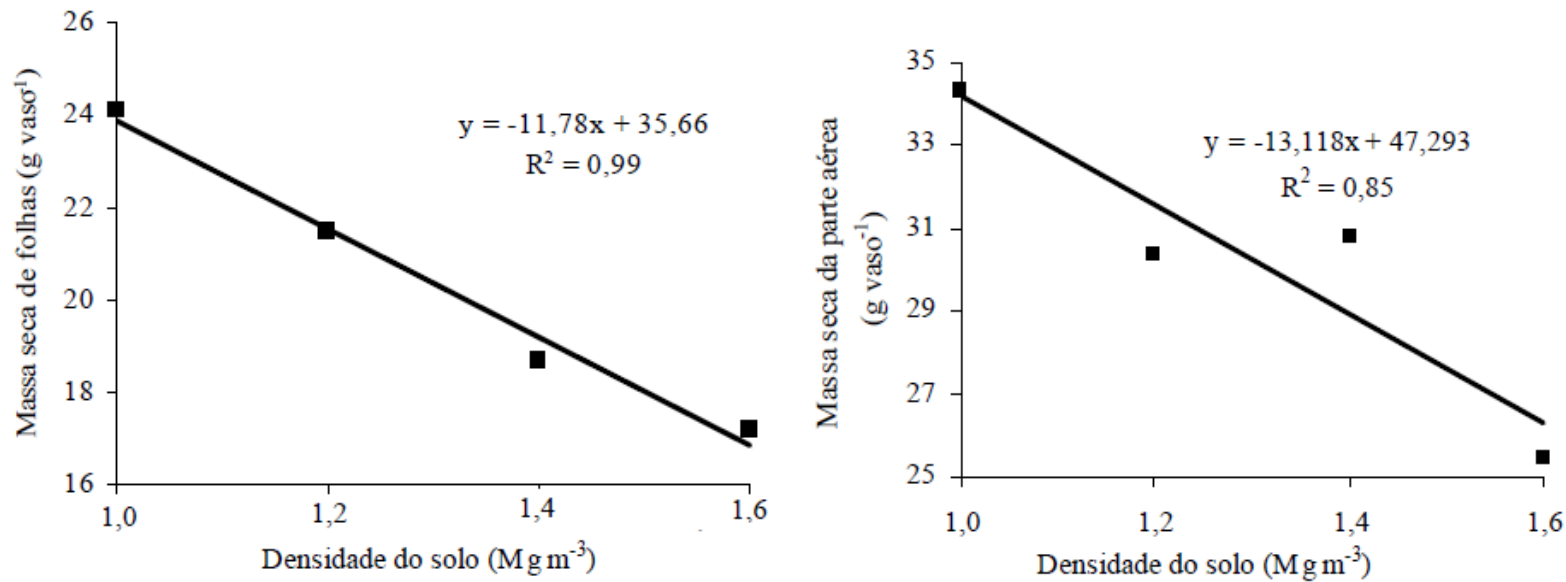

Figura 2. Massa seca da parte aérea (MSPA) das forrageiras capim-mombaça sob os níveis de compactação no segundo período de crescimento

Resultado similares são encontrados pois ao avaliarem o sistema de manejo do solo (sistema convencional e plantio direto) sobre a produção de biomassa do capim Tamzânia, observou-se baixa correlação linear entre a produtividade de matéria seca e a densidade do solo na camada superficial, no entanto é altamente significativa do ponto de vista espacial, independente do manejo do solo (18).

\section{Resposta ao manejo e desempenho animal}

O processo de desfolhação da pastagem é muito complexo, e a resposta do desempenho animal é influenciada pela interação de diversos fatores tais como o ambiente, solo, planta, animal. O aumento no desempenho dos animais é observado em animais em pastejo nos diferentes sistemas de manejo utilizados, principalmente quando são empregadas técnicas de forma planejada e orientada com base em dados consistentes e confiáveis.

Ao avaliarem diferentes alturas de manejo do pasto $(20,40,60$ e $80 \mathrm{~cm})$ em capim Tanzânia ( Megathyrsus maximus cv Tanzânia), em regime de lotação contínua com o número de animais variável, em que os animais foram alocados nas unidades experimentais, quando a altura do pasto atingiu aproximadamente $90 \mathrm{~cm}$, Canto et al. (20), observaram que conforme aumenta a altura do dossel aumenta a produção de MS, no entanto alturas do pasto entre 40 e $60 \mathrm{~cm}$, permitem quantidades adequadas de massa de folha verde, elevadas taxas de acúmulo de matéria seca e restringem os colmos na massa de forragem .

Quando avaliadas as características da biomassa do capim-tanzânia sob três frequências de desfolhação (85, 95 e 97\% da interceptação da radiação fotossinteticamente ativa - IRFA) e dois resíduos pós-pastejo (índices de área foliar residual de 1,0 e 1,8), os autores observaram que o período de descanso nesse pasto não deve ultrapassar $95 \%$ da radiação fotossinteticamente ativa, o índice de área foliar residual ideal é de 1,0 para evitar o sombreamento mútuo, possibilitar o perfilhamento e controlar o alongamento do colmo por 
maior período de tempo, e a estrutura pós-pastejo é fortemente afetada pelo índice de área foliar residual (9).

Ao avaliar as características agronômicas, a composição bromatológica e a cinética de fermentação ruminal dos componentes nutricionais do capim Tanzânia ( Megathyrsus maximus cv Tanzânia) colhido em cinco idades de corte (42, 63, 84, 107 e 126 dias Castro et al. (6), verificaram que, a produtividade, composição agronômica, composição bromatológica e cinética de fermentação ruminal apresentam os melhores valores nas idades de 42 a 63 dias de crescimento após o plantio para a confecção de silagem.

Em outro experimento realizado, para avaliar o valor nutritivo da forragem, o desempenho e a conversão alimentar de novilhos em pastos de Tanzânia submetidos a duas intensidades de pastejo com lotação intermitente (rotativa), (resíduos de 25 e $50 \mathrm{~cm}$ ), com taxa de lotação variável, associadas a intervalo de pastejo correspondente ao tempo necessário para que o dossel forrageiro interceptasse $95 \%$ da luz incidente durante a rebrotação (20). Verificaram que pastos manejados com resíduo de $50 \mathrm{~cm}$ apresentaram menores intervalos de pastejo, com média de 33 dias, enquanto que os manejados com resíduo de $25 \mathrm{~cm}$ apresentaram maiores intervalos de pastejo, com média de 50 dias, resultando em menor número de ciclos de pastejo ao final do experimento.

Estes autores observaram ainda que a proporção de colmo foi maior para os pastos manejados com resíduo pós-pastejo de $50 \mathrm{~cm}$. Na condição pós-pastejo, a massa de forragem variou com a altura de resíduo utilizada e o resíduo de $25 \mathrm{~cm}$ foi o que resultou em menor massa de forragem (Tabela 4). O maior acúmulo de colmo no resíduo pós-pastejo mais alto indica que, apesar desse manejo favorecer o desempenho individual dos animais (Tabela 5), essa forma de manejo apresenta menor controle da estrutura do dossel, o que vêm a prejudicar o acúmulo e o valor nutritivo da forragem produzida no médio e longo prazo. Foi observada a maior taxa de acúmulo quando o pasto foi manejado a $50 \mathrm{~cm}$ de altura de resíduo, entretanto mesmo com as maiores taxas, não houve diferença na massa de forragem pré-pastejo, pois, quanto maiores as taxas de acúmulo de forragem dos pastos, mais curtos foram os intervalos de pastejo (33 dias,). O maior intervalo de pastejo para o resíduo de $25 \mathrm{~cm}$ (50 dias) compensou a menor taxa de acúmulo em relação ao resíduo de $50 \mathrm{~cm}$.

Tabela 4. Interceptação luminosa (\%), altura do dossel pré e pós-pastejo $(\mathrm{cm})$, massa de forragem pré e pós-pastejo ( $\mathrm{kg} / \mathrm{ha}$ de $\mathrm{MS}$ ), taxa de acúmulo de MS ( $\mathrm{kg} / \mathrm{ha}$.dia) e composição morfológica da massa de forragem pré-pastejo (\%) de pastos de capimtanzânia submetidos a intensidades de pastejo rotativo de janeiro a maio de 2005

\begin{tabular}{lcc}
\hline \multicolumn{1}{c}{ Variável } & \multicolumn{2}{c}{ Altura de resíduo $(\mathrm{cm})$} \\
\cline { 2 - 3 } & 25 & 50 \\
\hline \hline Interceptação luminosa (\%) & 95,0 & 95,8 \\
Altura do dossel pré-pastejo (cm) & 65,0 & 68,4 \\
Altura do dossel pós-pastejo (cm) & 26,5 & 47,8 \\
Massa de forragem pré-pastejo (kg/há de MS) & $7130 \mathrm{a}(3,82)$ & $8600 \mathrm{a}(3,21)$ \\
Massa de forragem pós-pastejo (kg/ha de MS) & $3810 \mathrm{~b}(372,30)$ & $5080 \mathrm{a}(329,20)$ \\
Taxa de acúmulo de MS (kg/ha.dia de MS) & $90,6 \mathrm{~b}(8,60)$ & $164,9 \mathrm{a}(7,20)$ \\
Folha (\%) & $61,7 \mathrm{a}(0,17)$ & $59,6 \mathrm{a}(0,14)$ \\
Colmo (\%) & $13,4 \mathrm{~b}(0,03)$ & $15,9 \mathrm{a}(0,03)$ \\
Material morto (\%) & $25,0 \mathrm{a}(0,20)$ & $24,5 \mathrm{a}(0,17)$ \\
\hline \hline
\end{tabular}

Médias seguidas de mesma letra na linha não diferem $(\mathrm{P}>0,05)$ pelo teste Tukey. Valores entre parênteses representam os erros-padrão das médias (EPM).

Com os resultados obtidos os autores concluíram que a altura de resíduo $25 \mathrm{~cm}$ propicia maiores ganhos por área e maior uniformidade de produção, sendo que a altura de $50 \mathrm{~cm}$ de 
resíduo promove maior ganho individual e também maior número de ciclos de pastejo, sendo assim a escolha de qual altura de resíduo do pasto dependerá dos objetivos do sistema de criação e do nível de desempenho e produtividade.

Tabela 5. Ganho de peso médio diário, conversão alimentar e taxa de lotação em pastos de capim-tanzânia submetidos a intensidades de pastejo rotativo de janeiro a maio de 2005

\begin{tabular}{|c|c|c|c|}
\hline \multirow[t]{2}{*}{ Variável } & \multicolumn{2}{|c|}{ Altura de resíduo $(\mathrm{cm})$} & \multirow[t]{2}{*}{ Médias } \\
\hline & 25 & 50 & \\
\hline "Ganho médio diário (g/dia) & $664 \mathrm{~b}(0,03)$ & $801 \mathrm{a}(0,03)$ & 732 \\
\hline Conversão alimentar (kg MS consumida/kg & $10,3 \mathrm{a}(0,48)$ & $8,9 \mathrm{~b}(0,48)$ & 9,6 \\
\hline Taxa de lotação (animais de $300 \mathrm{~kg} / \mathrm{ha}$ ) & $6,1 \mathrm{a}(0,22)$ & $4,9 b(0,22)$ & 9,6 \\
\hline
\end{tabular}

Médias seguidas de mesma letra na linha não diferem $(\mathrm{P}>0,10)$ pelo teste Tukey.Valores entre parênteses representam os erros-padrão das médias.

Em outro experimento similar para avaliar as características estruturais e o acúmulo de forragem do capim-tanzânia sob pastejo rotativo e no período de 7/11/2005 a 12/10/2006, em Viçosa, Minas Gerais, submetido às combinações de duas frequências de pastejo (tempo para o dossel atingir 90 ou $95 \%$ de interceptação da luz - IL, que corresponderam a 65 e $75 \mathrm{~cm}$ respectivamente) e duas alturas pós-pastejo $(30 \mathrm{ou} 50 \mathrm{~cm})(22)$. Encontraram médias superiores para a produção de forragem sendo os resultados médios na altura de $30 \mathrm{~cm}$ e de $15740 \pm 82 \mathrm{e}$ $17270 \pm 382 \mathrm{~kg} \mathrm{ha}^{-1}$ e com 90 e $95 \%$ de IL respectivamente, e para a altura de $50 \mathrm{~cm}$ observouse uma produção de $13630 \pm 213$ e $13740 \pm 256$ para 90 e $95 \%$ de IL, respectivamente.

Os autores ainda concluem que para se conseguir maior acúmulo de forragem, o pastejo rotativo deve ser iniciado com $95 \%$ IL pelo dossel $( \pm 75 \mathrm{~cm}$ de altura) e rebaixado até $30 \mathrm{~cm}$ no pós-pastejo. Em situações específicas, o capim-tanzânia pode ser manejado com $90 \%$ IL pelo dossel ( $\pm 65 \mathrm{~cm}$ de altura) no pré-pastejo gerando assim maior flexibilidade no manejo do pastejo de acordo com as diferentes épocas do ano.

Ao avaliar as influências do período de descanso e altura do resíduo pós-pastejo sobre a massa seca de forragem, composição morfológica e sobre a composição química do capimtanzânia sob pastejo rotativo com dois períodos de descanso (d) (25 e 35 dias) e duas alturas de resíduo pós-pastejo (r) (30 e $50 \mathrm{~cm}$ ), Janusckiewicz, et al. (2010) observaram que os tratamentos 25d30r e 35d30r proporcionaram maior produção de folhas no terceiro ciclo de pastejo possivelmente pela ocorrência de chuvas bem distribuídas nesse período (Tabela 6).

Diante dos valores encontrados os autores concluem que apesar de não haver diferença estatisticamente significativa entre os diferentes tratamentos, verifica-se que a aplicação do manejo de 25 dias de descanso e altura de resíduo de $30 \mathrm{~cm}$ para esse cultivar proporciona maiores produções de matéria seca total, de folhas e de colmos e teores de PB, com menores teores de FDN.

Em um experimento realizado na Zona da Mata de Rondônia com a finalidade de avaliar o efeito de dois períodos de descanso ( 36 e 48 dias de rebrotação), com $25 \mathrm{~cm}$ de altura do corte sobre as características agronômicas, morfogênicas, estruturais e taxa de crescimento do capim Megathyrsus maximus cv. Mombaça a produção média em kg ha- ${ }^{1}$ foi de 3723,90 e 4989,10 para os períodos de descanso de 36 e 48 dias, respectivamente. Para a taxa de crescimento cultural, observaram os valores médios em Kg MS ha- ${ }^{1}$ dia-1 de 104,98 e 104,35 para os períodos de descanso de 36 e 48 dias. Entre as características estruturais avaliadas, observouse efeito dos tratamentos $(\mathrm{P}<0,10)$ somente para o comprimento de lâmina foliar, número de folhas mortas e relação folha colmo, e entre essas varáveis respostas, apenas o comprimento de lâmina foliar sofreu efeito negativo com o prolongamento do período de descanso. 
Tabela 6. Proporções de colmo (PC), lâmina foliar (PLF) e material morto (PMM) e relação folha:colmo (F:C) de capim-tanzânia sob lotação intermitente

\begin{tabular}{|c|c|c|c|c|}
\hline Tratamentos & $\mathrm{PC}(\%)$ & PLF (\%) & PMM (\%) & $\mathrm{F}: \mathrm{C}$ \\
\hline $25 \mathrm{~d} 30 \mathrm{r}$ & $30,73^{\mathrm{a}}$ & $58,34^{\mathrm{a}}$ & $10,93^{\mathrm{a}}$ & $2,44^{\mathrm{a}}$ \\
\hline $25 \mathrm{~d} 50 \mathrm{r}$ & $31,81^{\mathrm{a}}$ & $57,86^{\mathrm{a}}$ & $10,34^{\mathrm{a}}$ & $2,10^{\mathrm{a}}$ \\
\hline $35 \mathrm{~d} 30 \mathrm{r}$ & $32,55^{\mathrm{a}}$ & $58,64^{\mathrm{a}}$ & $8,81^{\mathrm{a}}$ & $2,22^{\mathrm{a}}$ \\
\hline $35 \mathrm{~d} 50 \mathrm{r}$ & $35,04^{\mathrm{a}}$ & $56,93^{\mathrm{a}}$ & $10,64^{\mathrm{a}}$ & $1,95^{\mathrm{a}}$ \\
\hline Média & 32,53 & 57,94 & 10,18 & 2,10 \\
\hline \multicolumn{5}{|l|}{ Ciclos de pastejo } \\
\hline $1^{\circ}$ & $18,14^{\mathrm{c}}$ & $71,73^{\mathrm{a}}$ & $10,13^{a}$ & $4,40^{\mathrm{a}}$ \\
\hline $2^{\circ}$ & $27,30^{\mathrm{b}}$ & $64,67^{\mathrm{ab}}$ & $8,04^{\mathrm{a}}$ & $2,42^{\mathrm{b}}$ \\
\hline $3^{\circ}$ & $35,10^{\mathrm{ab}}$ & $53,08^{\mathrm{c}}$ & $11,82^{\mathrm{a}}$ & $1,59^{\mathrm{cd}}$ \\
\hline $4^{\circ}$ & $31,45^{\mathrm{b}}$ & $60,97^{\mathrm{b}}$ & $7,57^{\mathrm{a}}$ & $2,02^{\mathrm{bc}}$ \\
\hline $5^{\circ}$ & $40,86^{\mathrm{a}}$ & $51,23^{\mathrm{c}}$ & $11,77^{\mathrm{a}}$ & $1,37^{\mathrm{d}}$ \\
\hline $6^{\circ}$ & $42,34^{\mathrm{a}}$ & $45,92^{c}$ & $11,74^{\mathrm{a}}$ & $1,14^{\mathrm{d}}$ \\
\hline Média & $32,53^{\mathrm{b}}$ & $57,94^{\mathrm{a}}$ & $10,18^{\mathrm{c}}$ & 2,10 \\
\hline $\mathrm{CV}(\%)$ & 19,87 & 10,81 & 45,60 & 25,09 \\
\hline
\end{tabular}

Médias seguidas por mesma letra maiúscula, nas colunas, e minúscula, na linha, não diferem entre si pelo teste de LS means a $5 \%$ de probabilidade; $\mathrm{CV}(\%)=$ coeficiente de variação

Com a finalidade de avaliar as características estruturais, morfológicas e produtivas em pastos de capim-mombaça sob lotação rotacionada com três períodos de descanso, definidos conforme o número de novas folhas expandidas por perfilho: 2,5, 3,5 e 4,5 folhas foram avaliadas as características: biomassa total, taxa de crescimento cultural, altura do dossel, (24) relação folha/colmo, índice de área foliar, interceptação da radiação, taxa de aparecimento e alongamento foliares, taxa de alongamento do colmo, densidade de perfilhos e coeficiente de extinção (Tabela 7).

Tabela 7. Valores médios de características estruturais e da biomassa de forragem em pastos de capim-mombaça no pré e pós-pastejo, submetidos a períodos de descanso (folhas por perfilho) $)^{1}$

\begin{tabular}{|c|c|c|c|c|c|c|c|c|c|}
\hline \multirow[t]{2}{*}{ Período de descanso } & \multicolumn{6}{|c|}{ Pré-pastejo } & \multicolumn{3}{|c|}{ Pós-pastejo } \\
\hline & $\begin{array}{l}\text { Altura } \\
(\mathrm{cm})\end{array}$ & IAF & $\begin{array}{l}\mathrm{IL} \\
(\%)\end{array}$ & $\begin{array}{c}\text { MS } \\
\left(\text { kg ha- }^{-1}\right)\end{array}$ & $\mathrm{F} / \mathrm{C}$ & $\begin{array}{c}\text { TCC } \\
\left(\mathrm{kg} \mathrm{ha-}^{1} \text { dia- }^{-1}\right)\end{array}$ & $\begin{array}{l}\text { Perf. } \\
\left(\mathrm{m}-{ }^{2}\right)\end{array}$ & $\begin{array}{c}\text { Altura } \\
(\mathrm{cm})\end{array}$ & IAF \\
\hline 2,5 folhas/perfilho & $79,1 \mathrm{c}$ & $9,1 \mathrm{~b}$ & $95,6 \mathrm{a}$ & $4.571 \mathrm{~b}$ & 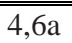 & $182,8 \mathrm{a}$ & $240,0 \mathrm{a}$ & 40,7 & 2,1 \\
\hline 3,5 folhas/perfilho & $97,9 \mathrm{~b}$ & $8,9 \mathrm{~b}$ & $95,5 \mathrm{a}$ & $5.584 \mathrm{ab}$ & $3,7 b$ & $159,5 b$ & $176,5 b$ & 44,2 & 1,5 \\
\hline 4,5 folhas/perfilho & $117,2 \mathrm{a}$ & $10,9 \mathrm{a}$ & $95,4 \mathrm{a}$ & $7.340^{\mathrm{a}}$ & $1,7 \mathrm{c}$ & $163,1 \mathrm{~b}$ & $148,4 \mathrm{c}$ & 50,0 & 1,4 \\
\hline $\mathrm{CV} \%$ & 12,5 & 15,4 & 1,5 & 19,2 & 21,9 & 11,3 & 22,4 & - & - \\
\hline
\end{tabular}

Médias seguidas pela mesma letra na coluna não diferem entre si pelo teste Tukey, a 5\% de probabilidade; AF, índice de área foliar; IL, interceptação luminosa; MS, matéria seca por ciclo de pastejo; F/C, relação folha/colmo; TCC, taxa de crescimento da cultura.

Os autores verificaram que com o aumento no número de ciclos de pastejo o percentual de alongamento do colmo aumenta, principalmente em períodos de descanso mais longos, e isso consequentemente compromete a estrutura do dossel, diminuindo a relação folha/colmo e o número de perfilhos, e o período de descanso não deve exceder o tempo para o aparecimento 
de três folhas adultas por perfilho, e ainda as adaptações morfológicas e estruturais do dossel forrageiro garantam sua satisfatória rebrotação sob o manejo de período de descanso de 2,5 novas folhas por perfilho, durante a época chuvosa (24).

Ao avaliarem as diferentes alturas do dossel $(60,80,100,120$ e $140 \mathrm{~cm})$ sobre o processo de ingestão de forragem verificaram que o percentual de PB da fração lâminas foliares referentes ao estrato médio superior do dossel diminuíram de 20,5 para 9,7\% com o aumento em altura do dossel, enquanto os teores de FDN e FDA apresentaram comportamento inverso. Verificaram ainda que a massa do bocado cresceu linearmente com o aumento da altura do dossel e a taxa de bocados praticada pelos animais decresceu linearmente, de 31 para 15 bocados/minuto entre as alturas de 60 e $140 \mathrm{~cm}$ respectivamente $(25)$.

Essa situação sugere que o tempo gasto pelo animal foi maior no processo de apreensão das lâminas foliares à medida que aumentaram em comprimento com a maior altura do dossel. A massa de forragem total consumida e a taxa de ingestão tornam-se estáveis nas maiores alturas do dossel, tendo em vista que o aumento no tempo por bocado foi proporcionalmente maior que o aumento da massa de bocado. Sugerindo que as limitações físicas impostas pela estrutura do dossel levaram a menor eficiência de captura de forragem pelos animais nas maiores alturas da pastagem. Observaram ainda que o maior consumo de forragem se deu à altura de 109,3 cm.

Para Alexandrino et al. (8), pastos de capim mombaça possuem a taxa de acúmulo de folhas até a altura do dossel de $75 \mathrm{~cm}$, sendo esta a altura máxima recomendada para o manejo. Já Carnevalli (26), a altura recomendada é $90 \mathrm{~cm}$ (95\% de interceptação luminosa), pois a partir desta altura aumenta-se o percentual de hastes, de material morto e diminui o percentual de lâminas foliares, além de diminuir a digestibilidade e o teor de proteína.

Ao classificar os genótipos de acordo com características produtivas Stabile et al. (27), verificaram que produção de MS diferiu entre os genótipos somente aos 90 dias de crescimento, mas a porcentagem de folhas, colmos e material morto variou tanto aos 60 como aos 90 dias de crescimento. Quando a participação de colmo no total de massa seca aumenta, esse componente passa a ser o limitador da qualidade de plantas forrageiras (Tabela 8).

Tabela 8. Produção de matéria seca verde e proporção de componentes da planta de 11 genótipos de capim-colonião colhidos em três idades de corte

\begin{tabular}{|c|c|c|c|c|c|c|c|c|c|c|}
\hline \multirow[b]{2}{*}{ D C } & \multicolumn{3}{|c|}{ PMSV (kg ha-1 $\left.{ }^{1}\right)$} & \multicolumn{2}{|c|}{ Folhas (\%MS) } & \multicolumn{3}{|c|}{ Colmos (\%MS) } & \multicolumn{2}{|c|}{ Material morto (\%MS) } \\
\hline & $30 \mathrm{~d}$ & $60 \mathrm{~d}$ & $90 \mathrm{~d}$ & $30 \mathrm{~d}$ & $60 \mathrm{~d} \quad 90 \mathrm{~d}$ & $30 \mathrm{~d}$ & $60 \mathrm{~d}$ & $90 \mathrm{~d}$ & $30 d$ & $60 \mathrm{~d} 90 \mathrm{~d}$ \\
\hline Massai & 3071 & 7067 & $11.437 \mathrm{~cd}$ & 87,3 & $77,4 \mathrm{bc} 70,7 \mathrm{a}$ & 12,7 & $12,4 \mathrm{bcd}$ & $14,6 \mathrm{c}$ & - & $10,1 \mathrm{ab} 14,7 \mathrm{bcd}$ \\
\hline Milênio & 4467 & 7014 & $18.238 \mathrm{ab}$ & 91,6 & $70,8 \mathrm{c} 50,2 \mathrm{bcd}$ & 8,4 & $25,8 \mathrm{a}$ & $41,7 \mathrm{a}$ & - & $3,4 \mathrm{~d} \quad 8,1 \mathrm{ef}$ \\
\hline Mombaça & 3938 & 4432 & $22.857 \mathrm{a}$ & 96,0 & $81,9 \mathrm{ab} 50,9 \mathrm{bcd}$ & 4,0 & $14,6 \mathrm{bcd}$ & $41,5 \mathrm{a}$ & - & $3,5 \mathrm{~d}$ \\
\hline Tanzânia & 3294 & 3734 & $14.907 \mathrm{bcd}$ & 84,3 & $76,7 \mathrm{bc} 47,0 \mathrm{~d}$ & 15,7 & $9,8 \mathrm{~cd}$ & $33,9 \mathrm{ab}$ & - & $13,4 \mathrm{a} 19,1 \mathrm{abc}$ \\
\hline EPM & 791 & 809 & 2.181 & 4,4 & $2,9 \quad 4,6$ & 4,36 & 3,14 & 4,93 & - & 2,2 \\
\hline 1 & $\mathrm{~ns}$ & $\mathrm{~ns}$ & $* *$ & ns & $* *$ & ns & $* *$ & $* *$ & - & $* *$ \\
\hline
\end{tabular}

PMSV: produção de matéria seca verde, em kg/ha. DC: dias de crescimento da planta, contados a partir de corte de nivelamento em 29/12/2005. EPM: erro-padrão da média. ${ }^{1}$ Probabilidade de efeito significativo de genótipo (teste F)

O autores ainda verificaram que existe grande variação entre os genótipos em relação ao efeito da maturidade sobre a digestibilidade do colmo, porém não há efeito dos genótipos sobre a digestibilidade das folhas, e quando comparadas ao colmo a digestibilidade das folhas é pouco afetada com o avanço da maturidade.

De acordo com Orrico et al. (27), ao avaliarem diferentes idades de corte para a confecção de silagem de capim massai, não encontraram diferenças mas características qualitativas do material ensilado nas idades de 35 a 63 dias. Devido a sazonalidade da intensidade luminosa e principalmente do regime de chuvas é importantes esclarecer que para os sistemas de produção a pasto (sistema de lotação contínua ou intermitente) devem ser executadas estratégias para o 
período de entressafra da produção de forragem (secas), estas estratégias podem ser de suplementação (com concentrado e/ou volumoso), variação da taxa de lotação, ou ambas.

Independentemente de outras variáveis para o capim-Massai e para as outras cultivares

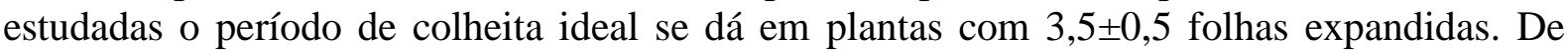
maneira geral para Megathyrsus maximus cv Tanzânia sob regime de lotação contínua e carga animal variável, recomenda-se a altura de pastejo entre 40 e $60 \mathrm{~cm}$, e para lotação intermitente (pastejo rotacionado) o ideal é a entrada com $\pm 65 \mathrm{~cm}$ de dossel (parte aérea) e 25 a $30 \mathrm{~cm}$ para o resíduo pós pastejo. Ao ser utilizado como silagem, este mesmo cultivar deve ser cortado entre 42 e 63 dias após o plantio. Para o capim-Mombaça em regime de lotação intermitente a entrada dos animais deve ocorrer com altura aproximada de $80 \mathrm{~cm}$ e saída de $40 \mathrm{~cm}$, e para lotação contínua a altura ideal é de 50 a $75 \mathrm{~cm}$.

\section{COMENTÁRIOS FINAIS}

O manejo correto das pastagens é um processo complexo devido às variações das condições climáticas ao longo do ano, diferentes tipos de solo (com características físicas e químicas diferentes), categorias e hábitos de pastejo das diferentes espécies animais, e ainda à grande diversidade de cultivares de capim que são lançados sem estudos necessários para o conhecimento do comportamento destas espécies e as aplicações práticas para a perfeita compreensão dos manejadores.

Adicionalmente podemos destacar ainda a falta de assessoria técnica para o aumento da eficiência produtiva essencial para que a grande maioria dos produtores saiam da condição de apenas exploradores dos recursos disponíveis necessários para a produção animal.

\section{AGRADECIMENTO}

À CAPES. O presente trabalho foi realizado com apoio da Coordenação de Aperfeiçoamento de Pessoal de Nível Superior - Brasil (CAPES) - Código de Financiamento 001

\section{REFERÊNCIAS}

1. Barbosa RA, Nascimento Júnior D, Euclides VPB, Silva SC, Zimmer AH, Torres Júnior RAA. Capim-tanzânia submetido a combinações entre intensidade e frequência de pastejo. Pesqui Agropecu Bras. 2007;42:329-40.

2. Neres MA, Castagnara DD, Silva FB, Oliveira PSR, Mesquita EE, Bernardi TC, et al. Características produtivas, estruturais e bromatológicas dos capins Tifton 85 e Piatã e do feijão-guandu cv. Super N, em cultivo singular ou em associação. Cienc Rural. 2012;42:862-9.

3. Leng RA. Decline in available world resources; implications for livestock production systems in Asia. Livest Res Rural Dev. 2008;20:1-8.

4. Cândido MJD, Silva RG, Neiva JMN, Facó O, Benevides YI, Farias SF. Fluxo de biomassa em capim-tanzânia pastejado por ovinos sob três períodos de descanso. Rev Bras Zootec. 2006;35:2234-42.

5. Zanine AM, Santos EM, Ferreira DJ. Possíveis causas da degradação de pastagens. Rev Electron Vet. 2005;6:1-23. 
6. Castro GHF, Rodriguez NM, Gonçalves LC, Maurício RM. Características produtivas, agronômicas e nutricionais do capim-tanzânia em cinco diferentes idades ao corte. Arq Bras Med Vet Zootec. 2010;62:654-66.

7. Oliveira TK, Macedo RLG, Santos IPA, Higashikawa EM, Venturin N. Produtividade de Brachiaria brizantha (Hochst. ex A. Rich.) Stapf cv. marandu sob diferentes arranjos estruturais de sistema agrossilvipastoril com eucalipto. Cienc Agrotec. 2007;31:748-57.

8. Alexandrino E, Candido MJD, Gomide JA. Fluxo de biomassa e taxa de acúmulo de forragem em capim Mombaça mantido sob diferentes alturas. Rev Bras Saude Prod Anim. 2011;12:59-71.

9. Cutrim Júnior JAA, Cândido MJD, Valente BSM, Carneiro MSS, Carneiro HAV. Características estruturais do dossel de capim-tanzânia submetido a três frequências de desfolhação e dois resíduos pós-pastejo. Rev Bras Zootec. 2011;40:489-97.

10. Oliveira PSR, Castagnara DD, Gonçalves Júnior AC, Mesquita EE, Neres MA. Teores de macrominerais em Panicum maximum cvs. massai e mombaça. Synergismus Scyentifica UTFPR. 2009;4:1-3.

11. Freitas KR, Rosa B, Ruggiero JA, Nascimento JL, Heinemam AB, Macedo RF, et al. Avaliação da composição químico-bromatológica do capim mombaça (Panicum maximum jacq.) submetido a diferentes doses de nitrogênio. Biosci J. 2007;23:1-10.

12. Silva AG, França AFS, Miyagi ES, Mello SQS, Ferreira JL, Carvalho ER. Frações proteicas do capim-mombaça submetido a doses de nitrogênio em duas alturas de corte. Arq Bras Med Vet Zootec. 2009;61:1148-55.

13. Ribeiro EG, Fontes ACC, Palieraqui JGB, Martins CE, Cóser AC, Sant'Ana NF. Influência da irrigação durante as épocas seca e chuvosa na taxa de lotação, no consumo e no desempenho de novilhos em pastagens de capim-elefante e capim-mombaça. Rev Bras Zootec. 2008;37:1546-54.

14. Janusckiewicz AR, Magalhães MA, Ruggieri AC, Reis RA. Massa de forragem, composição morfológica e química de capim-tanzânia sob diferentes dias de descanso e alturas de resíduo pós-pastejo. Biosci J. 2010;26:161-172.

15. Volpe E, Marchetti ME, Macedo MCM, Lempp B. Acúmulo de forragem e características do solo e da planta no estabelecimento de capim-massai com diferentes níveis de saturação por bases, fósforo e nitrogênio. Rev Bras Zootec. 2008;37:228-37.

16. Zanine AM, Dias PF, Souto SM, Ferreira DJ. Avaliação do capim-tanzânia (Panicum maximum) por meio de métodos de análise Multivariada. Rev Bras Saude Prod Anim. 2008;9:179-89.

17. Souza MRF, Pinto JC, Oliveira IP, Muniz JA, Rocha GP, Evangelista AR. Produção de forragem do capim-tanzânia sob intervalosde corte e doses de potássio. Cienc Agrotec. 2007;31:1532-6. 
18. Vitória EL, Fernandes HC, Teixeira MM. Correlação linear e espacial entre produtividade de capim-mombaça e atributos físicos solo em função do sistema de manejo. Rev Agrotec. 2011;2:30-43.

19. Bonelli EA, Bonfim-Silva EM, Cabral CEA, Campos JJ, Scaramuzza WLMP, Polizel AC. Compactação do solo: Efeitos nas características produtivas e morfológicas dos capins Piatã e Mombaça. Rev Bras Eng Agríc Ambient. 2011;15:264-9.

20. Canto MW, Jobim CC, Gasparino E, Hoeschl AR. Características do pasto e acúmulo de forragem em capim-tanzânia submetido a alturas de manejo do pasto. Pesqui Agropecu Bras. 2008;43:429-35.

21. Difante GS, Euclides VPB, Nascimento Júnior D, Silva SC, Barbosa RA, Torres Júnior RAA. Desempenho e conversão alimentar de novilhos de corte em capim-tanzânia submetido a duas intensidades de pastejo sob lotação rotativa. Rev Bras Zootec. 2010;39:33-41.

22. Zanine AM, Nascimento Júnior D, Santos MER, Pena KS, Silva SC, Sbrissia AF. Características estruturais e acúmulo de forragem em capim-tanzânia sob pastejo rotativo. Rev Bras Zootec. 2011;40:2364-73.

23. Macedo CHO, Alexandrino E, Jakelaitis A, Vaz RG, Reis RHP, Vendrusculo J. Características agronômicas, morfogênicas e estruturais do capim Panicum maximum cv. Mombaça sob desfolhação intermitente. Rev Bras Saude Prod Anim. 2010;11:941-52.

24. Gomide CAM, Gomide JA, Alexandrino E. Características estruturais e produção de forragem em pastos de capim-mombaça submetidos a períodos de descanso. Pesqui Agropecu Bras. 2007;42:1487-94.

25. Palhano AL, Carvalho PCF, Dittrich JR, Moraes A, Silva SC, Monteiro ALG. Características do processo de ingestão de forragem por novilhas holandesas em pastagens de capim-mombaça. Rev Bras Zootec. 2007;36:1014-21.

26. Carnevalli RA. Dinâmica da rebrotação de pastos de capim-Mombaça submetidos a regimes de desfolhação intermitente [tese]. Piracicaba: ESALQ; 2003.

27. Stabile SS, Salazar DR, Jank L, Rennó FP, Prada e Silva LF. Características de produção e qualidade nutricional de genótipos de capim-colonião colhidos em três estádios de maturidade. Rev Bras Zootec. 2010;39:1418-28.

Recebido em: 27/11/2019 Aceito em: 29/06/2020 